\title{
HISTOLOGICAL ANALYSIS OF WISTAR RATS SCIATIC NERVES SUBJECTED TO COMPRESSION AND TREATED WITH LOW LEVEL LASER THERAPY AND NEURAL MOBILIZATION
}

Juliana Sobral Antunes ${ }^{1}$, Jhenifer Karvat ${ }^{1}$, Giovanni Ribeiro Bernardino ${ }^{2}$, Camila Mayumi Martin Kakihata ${ }^{1}$, Rose Meire Costa Brancalhão ${ }^{1}$, Lucinéia de Fátima Chasko Ribeiro ${ }^{1}$, Fernando Amâncio Aragão ${ }^{2}$, Gladson Ricardo Flor Bertolini ${ }^{1,2}$

Correspondence: gladsonricardo@gmail.com

${ }^{1}$ Bioscience and Health of State University of West Paraná - Unioeste, Brazil.

${ }^{2}$ Physical Therapy of State University of West Paraná - Unioeste, Brazil.

Article History:

Received: August 24, 2018

Accepted: December 11, 2018

Published: July 1, 2019

\section{Cite this as:}

Antunes JS, Karvat J, Bernardino GR, Kakihata CMM, Brancalhão $R M C$, Ribeiro LFC, et al . Histological analysis of wistar rats sciatic nerves subjected to compression and treated with low level laser therapy and neural mobilization. Malang Neurology Journal; 2019.5:55-60. DOI: http://dx.doi.org/10.21776/ub.mnj .2019.005.02.1

\section{ABSTRACT}

Background: The physical therapy resources, as Low-Level Laser Therapy (LLLT) and neural mobilization are usually used with regenerative purpose and for the relief of symptoms for peripheral nerve injury. However, there is a lack of consensus on its effects as well as its association.

Objective: Evaluate the influence of low-level laser therapy (LLLT) associated with neural mobilization (NM) on nerve regeneration of female Wistar rats subjected to sciatic compression. Methods: Twenty four Wistar rats were divided into: G1 (Placebo), G2 (NM), G3 (LLLT) and G4 (NM+LLLT), all animals were subject to compression of the right sciatic nerve. The treatment occurred on the $3^{\text {rd }}, 5^{\text {th }}, 7^{\text {th }}, 10^{\text {th }}, 12^{\text {th }}$ and $14^{\text {th }}$ postoperative day (PO). On the $17^{\text {th }}$ PO the animals were euthanized. Histological and morphometric analysis of the right (compression) and the left (control) sciatic nerve were performed.

Results: In the morphometric analysis no significant differences between groups, but differences among sides were found. Histological analysis revealed the presence of inflammatory infiltrate and disruption of nerve fibers in the right sciatic nerves.

Conclusion: Both techniques used (LLLT and neural mobilization), isolated and associated, on the parameters proposed, were not effective to accelerate the process of nerve regeneration.

Keywords: Nerve Regeneration, Sciatic Nerve, Physical Therapy Modalities

\section{Introduction}

Within the compressive nerve lesions of the lower limbs is common the presence of sciatica, a well located pain in the lower limbs that radiates down along the posterior side of the leg, which has been often associated with limb numbness. ${ }^{1,2}$ A herniated disc in the low back is usually the main cause of sciatica; however, numerous extra spinal pathologies can affect the lumbosacral plexus becoming the origin of symptoms like pain, paresthesia, anesthesia and muscle weakness. This condition leads to serious economic consequences due to subject's inability to work and the difficulty in treatment related to pain control, ${ }^{1}$ causing higher treatment costs as a consequence of the greater recovery time compared to cases of just low back pain. ${ }^{3}$

Several types of treatments for peripheral nerve injury are established or tested ${ }^{4,5}$ and the physical therapy resources are usually used with regenerative purpose and for the relief of symptoms. The Low-Level Laser Therapy (LLLT) ${ }^{6}$ and neural mobilization, ${ }^{7}$ as examples, target on effective recovery function during rehabilitation. ${ }^{8}$ The LLLT acts as moderator of the local inflammatory reaction in the early stages of tissue injury, thus assisting the inflammation and pain reductions. ${ }^{9}$ Moreover, the LLLT is a feature widely used to accelerate the regenerative processes, promoting early functional return, ${ }^{10}$ with reports of moderate evidence for functional, biochemical and morphological recovery after nerve compression. ${ }^{11-14}$ In the neural mobilization technique, therapists performs passive movements in the segments, focusing on restoring the nervous system's ability to tolerate normal forces of tension, compression and friction. This technique aims to improve the neurodynamics and restore the axoplasmic flow of nervous tissues, ${ }^{15}$ with subsequent spasm $^{16}$ and pain reduction. ${ }^{17,18}$

Considering the importance of finding ways for the treatment of peripheral nerve injuries, and the lack of conclusive results related to the association of LLLT and neural mobilization on the regeneration of peripheral nerves, the aim of this study was to evaluate the influence of LLLT and neural mobilization on the sciatic nerve regeneration of female Wistar rats submitted to experimental nerve compression, based on the histologic and histomorphometric analysis. 


\section{Methods}

This was an exploratory, quantitative and qualitative study, and was approved by the Local Ethics Committee for Animal Research - CEUA, from Universidade Estadual do Oeste do Paraná - Unioeste (protocol n 002/13).

\section{Experimental Groups}

The sample group consisted of 24 female Wistar rats, with an average age of 10 weeks, obtained from the Unioeste central vivarium, which were kept in standard polypropylene cages, this sample size was based on previous studies..$^{11-14}$ The temperature of $23 \pm 1^{\circ} \mathrm{C}$, and light/dark cycle of 12 hours were controlled and the animals had water and food ad libitum.

The animals were randomly divided into four groups of six animals. Group 1 (G1): the animals were subjected to sciatic nerve compression and application of placebo treatment; Group 2 (G2): compression of the sciatic nerve and treated with neural mobilization; Group 3 (G3): sciatic nerve compression and application of LLLT, 830nm; Group 4 (G4): compression of the sciatic nerve and treated with neural mobilization and LLLT.

\section{Injury Protocol}

All animals were subjected to a sciatic nerve compression injury, therefore they were anesthetized with ketamine $(95 \mathrm{mg} / \mathrm{kg})$ and xylazine hydrochloride $(12 \mathrm{mg} / \mathrm{kg})$ intraperitoneally. After checking the state of consciousness of the animal (by clamping the tail and interdigital folds) the trichotomy of right thigh and asepsis with $70 \%$ alcohol was performed. A parallel incision to the fibers of the biceps femoris muscle of the right thigh was made, exposing the sciatic nerve. Following the model of Bennett and $\mathrm{Xie}^{19}$ a compression of the sciatic nerve was performed using a 4.0 chromed catgut in three regions ( $1 \mathrm{~mm}$ distance) along the nerve, then an external suture and the application of iodine was performed at the incision site.

\section{LLLT Protocol}

For the LLLT treatment, an $830 \mathrm{~nm}$ wavelength equipment with $30 \mathrm{~mW}$ output power, $0.12 \mathrm{~cm}^{2}$ spot, and $4 \mathrm{~J} / \mathrm{cm}^{2}$ dose was used. The total LLLT energy deposited was $0.48 \mathrm{~J}$. at each single application per session directly on the surgical incision. ${ }^{17}$ The animals were previously anesthetized as mentioned early, and the G1 was subjected to the same procedure, but with the laser equipment switched off. To guarantee the exact treatment dose, the laser output power was previously measured and the LLLT treatment was applied in the $3^{\text {rd }}, 5^{\text {th }}, 7^{\text {th }}, 10^{\text {th }}, 12^{\text {th }}$ and $14^{\text {th }}$ postoperative days by the same person.

\section{Neural Mobilization Protocol}

To perform the treatment with neural mobilization, the animals were anesthetized, and the technique was applied to the right hind limb. The animal was positioned in supine position with the hip flexed to approximately $70^{\circ}$, and the highest knee extension and ankle dorsiflexion up to the position of motion resistance. Then the ankle was subjected to 30 passive movements of planti and dorsiflexion, during one minute. In G1 the animals were sedated and maintained for 1 minute positioned lifting the right hind limb. The treatment with neural mobilization was performed on the same days of LLLT and the technique was always applied by the same person. ${ }^{20}$
The G4 group received both neural mobilization and LLLT therapies, in this order, as described above and always in the right hind limb.

\section{Morphometric Analysis}

On the $17^{\text {th }}$ postoperative day the animals were anesthetized and the sciatic nerve was dissected to collect a sample fragment of $1 \mathrm{~cm}$ distal to the compression procedure. To establish a benchmark for comparison, $1 \mathrm{~cm}$ of the sciatic nerve of the contralateral limb was dissected. Then, still under the effect of the anesthetic drugs, all animals were euthanized by guillotine decapitation. The fragments of the nerves were fixed in $10 \%$ formalin, included in paraffin and subjected to transverse sections of $7 \mu \mathrm{m}$ thick, with subsequent staining with hematoxylin and eosin (HE).

The histological slides were analyzed, the same blind reading person, based on the following parameters: nerve fibers diameter (NFD), myelin sheath diameter (MSD), axon diameter (AXD), number of axons per quadrant and $G$ ratio (MSD/NFD). To observe these histological variables an Olympus BX 50 light microscope was used, a piece of each nerve was selected and the slide view was photographed with the 10x objective to estimate the nerve area (ENA). In addition, the 100X objective was used to capture images to estimate the NFD, MSD and AXD and to perform the axon counting and to obtain the $G$ ratio value. For both images, 4 visual fields were captured, located systematically in the top right and left, bottom left and right, following the recommendations of Geuna et al. ${ }^{21}$

All morphometric measurements were taken from the images analyzed with Image-Pro Plus 6.0 software. For the axon counting one criteria was established, all axons that were in contact with the edges of the image called "inclusion" (left and top edges), were included; on the other hand, those axons which were in contact with the edges called "exclusion" (right and bottom edges) were excluded. The measurement of the NFD, MSD and AXD was performed for 100 axons per nerve in order to obtain an equivalent number for the comparisons between the nerves.

\section{Histological Analysis}

In the histological analysis, nerve constituents, such as epineurium, perineurium and endoneurium, as well as the nerve fiber, presence of inflammatory infiltrates, Schwann cells, fibroblasts and blood vessels were analyzed based on the images taken from both hind limbs of the four groups.

\section{Statistical Analysis}

The data was analyzed using descriptive and inferential statistics. The normality of data was analyzed by the Kolmogorov-Smirnov test and to evaluate the histomorphometric analysis, the data were subjected to statistical test for mixed measures (ANOVA). In all cases the level of significance was $\alpha=5 \%$.

\section{Results}

\section{Histomorphometric Evaluation}

For the ENA, no significant difference was observed $(\mathrm{F}(1,19)=0.16, \mathrm{p}=0.900)$. The same was found for AXD $(\mathrm{F}(1,19)=1.40, \mathrm{p}=0.251)$ (Table 1$)$.

However, the NFD was different $(F(1,19)=12.16, p=0.002)$, and although there were no differences among groups $(\mathrm{p}=1.000)$, a significant difference was found between 
limbs $(\mathrm{p}=0.002)$ where the right side was smaller than the left. The same occurred in the evaluation of MSD $(F(1,19)=16.54, p=0.001)$, where differences were found only between right and left limbs $(p=0.001)$. The same happened to axons number $(\mathrm{F}(1,19)=49.04, \mathrm{p}<0.001)$, and the $\mathrm{G}$ ratio $(\mathrm{F}(1,19)=4.88, \mathrm{p}=0.040)$ where the values on the right (injured limb) were smaller than those on the left (control limb) (Table 2).

\section{Histologic Evaluation Results}

Microscopic analysis of the sciatic nerve of the left side (control) (Fig. 1A and B) showed that nerve fibers had different diameters, with Schwann cell's nuclei peripheral to the myelin sheath, nuclei of fibroblasts and blood capillaries in endoneurium. The perineurium (Fig. 1A), of modeling connective tissue, was involving the entire nerve, forming concentric layers around it, and also squamous nuclei of fibroblasts could be visualized. Adjacent to the perineurium the epineurium was observed (Fig. 1A) also consisting of connective tissue, although not modeled. In nerve fibers the axons and the space of the myelin sheath were observed (Fig. 1B).

The analysis of the sciatic nerve on the right (lesioned) of all groups (G1, G2, G3 and G4; Fig.1 C-F) had the epineurium and perineurium arranged and similar to the left side (not shown). In addition, nerve fibers from different sizes, Schwann cells, fibroblasts nuclei and blood capillaries were present. However, in some samples, the nerve fibers were found to be disorganized and on the endoneurium a large amount of inflammatory infiltrate cold be seen, which hampered the best visualization of nerve fibers and axons. However, for some nerves of G1 and G2 the fibers were present in an organized manner and no inflammatory infiltrate was seen.

Table 1. Results of histomorphometric analysis of sciatic right (R) and left (L) (mean \pm standard deviation, in micrometers - $\mu \mathrm{m}$ ), to estimate the nerve area (ENA) and axon diameter (AXD).

\begin{tabular}{llcc}
\hline & & R & L \\
\hline & G1 & 701597 SD 311973 & 373383 SD 165739 \\
ENA & G2 & 602289 SD 464037 & 607273 SD 287375 \\
$(\boldsymbol{\mu m})$ & G3 & 357145 SD 46192 & 601773 SD 389261 \\
& G4 & 430696 SD 152164 & 684571 SD 185989 \\
ENA & G1 & 3.596 SD 0.739 & 3.738 SD 0.227 \\
$(\boldsymbol{\mu m})$ & G2 & 3.157 SD 0.218 & 3.860 SD 0.554 \\
& G3 & 3.940 SD 0.384 & 3.870 SD 0.943 \\
& G4 & 3.791 SD 0.601 & 3.822 SD 0.292 \\
\hline
\end{tabular}

Table 2. Results of histomorphometric analysis of sciatic right $(\mathrm{R})$ and left $(\mathrm{L})$ (mean \pm standard deviation, in micrometers $-\mu \mathrm{m})$ for the nerve fiber diameter (NFD), myelin sheath diameter (MSD), number of axons and G ratio.

\begin{tabular}{|c|c|c|c|}
\hline & & $\overline{\mathbf{R}}$ & $\mathbf{L}$ \\
\hline \multirow{4}{*}{$\begin{array}{l}\text { NFD * } \\
(\mu \mathrm{m})\end{array}$} & G1 & 8.423 SD 1.043 & 9.986 SD 1.883 \\
\hline & $\mathrm{G} 2$ & 8.189 SD 0.557 & 9.567 SD 0.630 \\
\hline & G3 & 9.015 SD 0.899 & 9.711 SD 1.009 \\
\hline & G4 & 8.788 SD 0.599 & 9.814 SD 0.565 \\
\hline \multirow{4}{*}{$\begin{array}{c}\text { MSD } * \\
(\mu \mathrm{m})\end{array}$} & G1 & 4.828 SD 0.363 & 6.248 SD 1.694 \\
\hline & $\mathrm{G} 2$ & $5.032 \mathrm{SD} 0.603$ & 5.707 SD 0.611 \\
\hline & G3 & 5.074 SD 0.536 & 5.840 SD 0.488 \\
\hline & G4 & 4.997 SD 0.259 & 6.032 SD 0.559 \\
\hline \multirow{4}{*}{$\underset{(\mu \mathrm{m})}{\operatorname{AXON}} \underset{ }{\text { NUMBERS }} *$} & G1 & 299.7 SD 280.0 & 446.5 SD 79.2 \\
\hline & $\mathrm{G} 2$ & 149.2 SD 236.1 & 445.7 SD 168.6 \\
\hline & G3 & 42.2 SD 19.5 & 452.7 SD 114.9 \\
\hline & G4 & 44.0 SD 23.2 & 492.3 SD 136.2 \\
\hline \multirow{4}{*}{$\underset{(\mu \mathrm{m})}{\operatorname{G~RATIO}} *$} & G1 & 0.423 SD 0.039 & 0.382 SD 0.051 \\
\hline & $\mathrm{G} 2$ & 0.387 SD 0.037 & 0.403 SD 0.051 \\
\hline & G3 & 0,437 SD 0.010 & 0.395 SD 0.064 \\
\hline & G4 & 0.429 SD 0.044 & 0.390 SD 0.032 \\
\hline
\end{tabular}

*significant difference between the sides $\mathrm{R}$ and $\mathrm{L}(\mathrm{p}<0,05)$. 

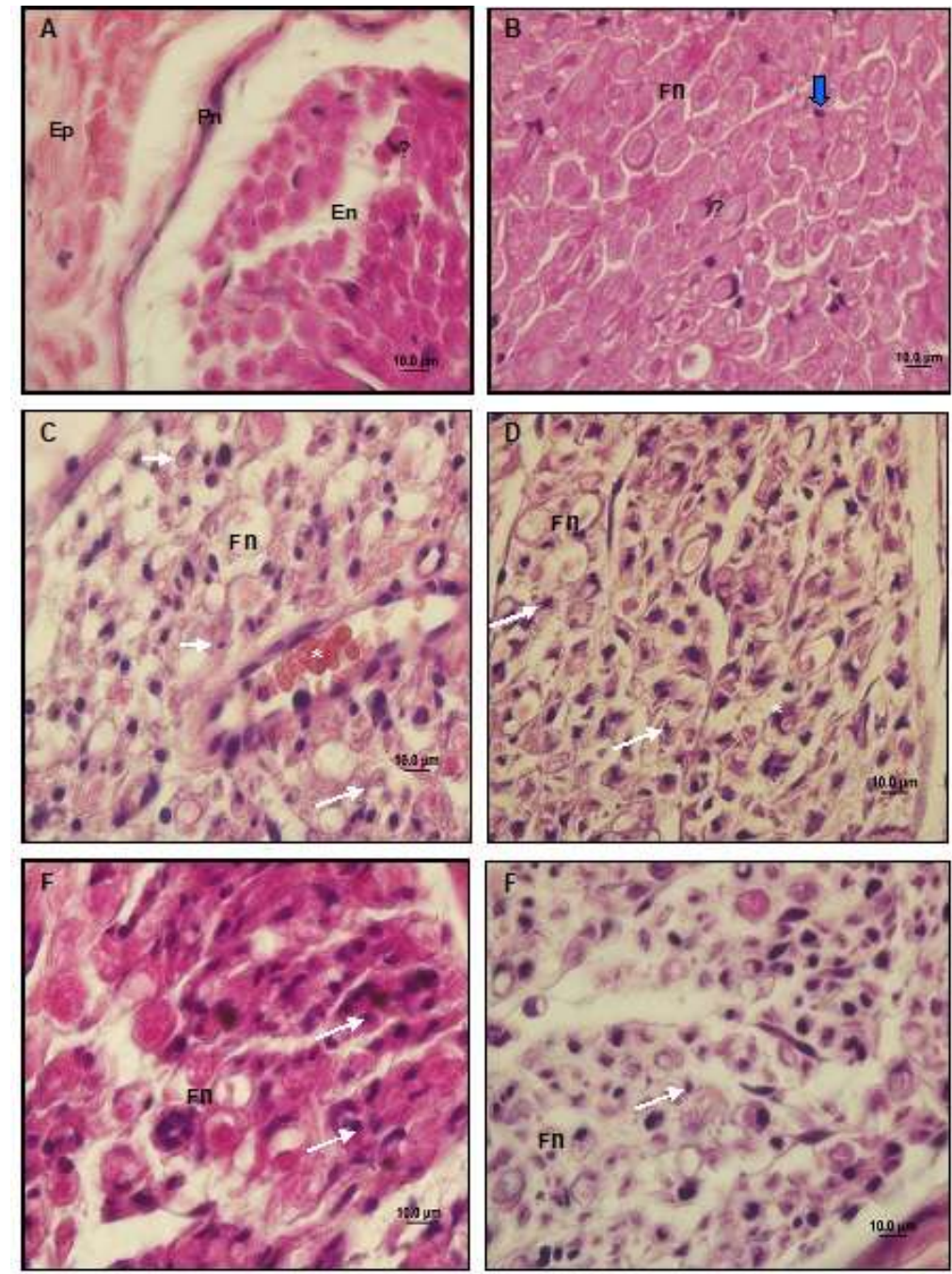

Figure 1. A - F. Photomicrographs of cross section of the distal segment of Wistar rats sciatic nerve, hematoxylin and eosin, Fn (nerve fiber), white arrow (inflammatory cells). In A, we see G1-side control, Ep (epineurium), Pn (perineurium), En (endoneurium) and nucleus of an apparent Schwann cell (arrowhead). In B, G1 - control, details of the axon and myelin sheath, likely Schwann cell (arrowhead) and fibroblasts (blue arrow). In C, we see G1 (injured) - showing inflammatory cells (white arrow) and blood vessel (*). D, group G2, in E G3 and F we see G4 - all injured and treated respectively with LLLT and neural mobilization in association.

\section{Discussion}

In the present study the morphometric variables like nerve area estimation and axon diameter did not show significant change neither among any of the groups, nor when comparing limbs, i.e., none of the proposed treatments for the experimental lesion was able to modify these parameters. For the nerve fibers, myelin sheaths diameter, axon number and $G$ ratio, statistically significant differences were observed when comparing sides, with the left (uninjured) side showing better results compared to the right (injured), as expected. Similarly, Sousa et $\mathrm{al}^{22}$ evaluated the LLLT effect on the peroneal nerve regeneration and observed that the LASER was not effective, with little or no influence on nerve regeneration parameters; the authors used $830 \mathrm{~nm}, 10.34 \mathrm{~J} / \mathrm{cm}^{2}$, applied for 14 consecutive days from the $1^{\text {st }}$ postoperative day, both in the region of the surgical incision and in the corresponding spinal nerve segment. However, Alcântara et $\mathrm{al}^{23}$ using much higher energy density $\left(60 \mathrm{~J} / \mathrm{cm}^{2}\right), 660 \mathrm{~nm}$, in 2 points, 24 hours after a sciatic nerve crush model for rats, observed that the LLLT induced the modulatory effect on inflammation. In contrast, Gonçalves et $\mathrm{al}^{6}$ using a dosage similar from our study $\left(4 \mathrm{~J} / \mathrm{cm}^{2}\right)$, also found that the LLLT $(830 \mathrm{~nm})$ application for sciatic nerve regeneration during 14 consecutive days generated significantly less inflammatory infiltrate and significantly greater amount of fibroblasts compared to placebo.

Thus, one can assume that the lack of results of the present study related to LLLT, regarding nerve regeneration, may be due to its small dosage, as it was applied only once per session, and the delay to start the treatment. However, Endo et $\mathrm{al}^{24}$ while verifying the effect of LLLT on the sciatic nerve regeneration with a $904 \mathrm{~nm}$ probe, applied for 10 minutes in the area of the surgical incision, starting on the $1^{\text {rst }}$ postoperative day and applied for 10 consecutive days, found that the number of axons was significantly higher in the laser-treated group compared to the placebo group, indicating that the therapy significantly contributed to nerve regeneration.

Similarly, in this study, the neural mobilization treatment did not show significant positive difference regarding the morphometric variables. One may argue that it also have occurred due to the delay to start the treatment $\left(3^{\text {rd }}\right.$ postoperative day) and the short application time of the technique (only 1 minute per session). However, Martins et $\mathrm{al}^{25}$ evaluating the use of planti and dorsiflexion mobilizations in rats subjected to sciatic nerve crush, observed a reduction of nociception and a better 
regeneration after a protocol starting on the $1^{\text {st }}$ and $5^{\text {th }}$ postoperative days on alternated days during 15 sessions, where each day of treatment, 3 sessions of 3 minutes with a 30-second interval were performed.

Corroborating the present study, we can mention the study of Marcioli et $\mathrm{al}^{26}$ which aimed to verify the effectiveness neural mobilization, for 1 or 3 minutes on the median nerve compression of rats, and did not obtain significant results regarding the nerve NFD, AXD, MSD and $G$ ratio. Moreover, the authors found that the number of axons was slightly lower in the group treated with neural mobilization for 3 minutes, these findings reveal a possible problem regarding the technique application, which may contribute to the lack of positive results. The pain absence as neural mobilization intensity increases due to animal's sedation during this procedure might be a limitation. On the other hand, in human studies this bias is abolished as mobilization is performed gently, avoiding harmful stimuli.

Silva et $\mathrm{al}^{7}$ evaluated the use of neural mobilization technique in humans with sciatica and observed that using the technique for 3 minutes, moderate benefits were showed, however, after seven minutes, the distal symptoms of sciatica worsened. De-La-Llave-Rincon et $\mathrm{al}^{27}$ also observed reduced pain in women with carpal tunnel syndrome who underwent neural mobilization, fact also reported by Oskay et $\mathrm{al}^{28}$ regarding the use of neural mobilization techniques in 7 patients with carpal tunnel syndrome. Nagrale et $\mathrm{al}^{29}$ treating individuals with nonradicular low back pain, suggested that slump stretching with spinal mobilization and stabilization exercises improves disability, pain and the fear-avoidance behavior. However, Ellis and Hing, in a systematic review, indicate that there is a lack of research available concerning this topic, with limited method quality and quantity, revealing few reliable evidences to support the use of neural mobilization. $^{30}$

Regarding the group that received the two treatment techniques, no significant difference was observed in comparison with the other groups, therefore, no evidences of treatment interaction was found, but, up to our knowledge, no other studies using these two therapeutic modalities together, to discuss and confront our results, were found in the literature to this moment.

On histologic examination, the injured side showed extensive inflammatory infiltrate and disorganized nerve fibers, similar in all groups, so that no treatment modality employed was superior to another. These results were surprising as previous research conducted in our laboratory, but using male rats, had pointed to analgesic characteristics related both to the LLLT $^{31}$ and to neural mobilization ${ }^{32}$ in this type of experimental injury. One should take into account that a large amount of inflammatory infiltrate in the samples was observed, showing that the treatment modalities were not effective for moderating the inflammatory process, which is important for neuropathic pain generation. ${ }^{33}$

\section{Conclusion}

The LLLT and neural mobilization, in the parameters used, isolated or associated, were not effective to accelerate sciatic nerve regeneration in female Wistar rats.

\section{Acknowledgement}

There was no financial sponsorship from any external body.

\section{References}

1. Lewis R, Williams N, Matar HE, Din N, Fitzsimmons D, Phillips C, et al. The clinical effectiveness and cost- effectiveness of management strategies for sciatica: systematic review and economic model. Health Technol Assess (Rockv); 2011.15(39):1-578. DOI: $10.3310 /$ hta15390

2. Ailianou A, Fitsiori A, Syrogiannopouou A, Toso S, Viallon M, Merlini L, et al. Review of the principal extra spinal pathologies causing sciatica and new mri approaches. Br J Radiol; 2012.85(1014):672-81. DOI: 10.1259/bjr/84443179

3. Ashworth J, Konstantinou K, Dunn KM. Prognostic factors in non-surgically treated sciatica: a systematic review. BMC Musculoskelet Disord; 2011.12. DOI: 10.1186/1471-2474-12-208

4. Kristianto H, Mardiati NPJ. The effects of earthworms' (pheretima aspergillum) ethanol extract toward the improvement of nerve fibers density in diabetic ulcers care degree ii of rats. Malang Neurology Journal; 2017.3:61-72. DOI: 10.21776/ub.mnj.2017.003.02.3

5. Malshikare VA, Desai SM, Arekar AS, Bhosale NA, Bonde SR, Awadhani MA. Comparison of Carpastretch ${ }^{\circledR}$ with splint in non-surgical treatment of carpal tunnel syndrome: a randomized open label study. Malang Neurology Journal; 2019.5:14-20. DOI: 10.21776/ub.mnj.2019.005.01.3

6. Gonçalves RB, Marques JC, Monte-raso VV, Zamarioli A, Carvalho LC, Fazan VPS, et al. Efeitos da aplicação do laser de baixa potência na regeneração do nervo isquiático de ratos /Effects of low-power laser on injured rat sciatic nerve regeneration. Fisioter Pesqui; 2010.17(1):34-9. DOI: 10.1590/S180929502010000100007

7. Silva LI, Rocha BP, Antunes JS, Karvat J, Kakihata CMM, Mattjie TF, et al. Evaluation of the pressure pain threshold after neural mobilization in individuals with sciatica. Eur J Physiother; 2013.15(July):146-50. DOI: $10.3109 / 21679169.2013 .831119$

8. Udina E, Puigdemasa A, Navarro X. Passive and active exercise improve regeneration and muscle reinnervation after peripheral nerve injury in the rat. Muscle Nerve; 2011.43(4):500-9. DOI: 10.1002/mus. 21912

9. Alves ACA, Carvalho P de TC de, Parente M, Xavier M, Frigo L, Aimbire F, et al. Low-Level laser therapy in different stages of rheumatoid arthritis: a histological study. Lasers Med Sci; 2013.28(2):52936. DOI: 10.1007/s10103-012-1102-7

10. Reis FA, Belchior ACG, Carvalho P de TC de, Silva BAK da, Pereira DM, Silva IS, et al. Effect of laser therapy $(660 \mathrm{~nm})$ on recovery of the sciatic nerve in rats after injury through neurotmesis followed by epineural anastomosis. Lasers Med Sci; 2009.24(5):741-7. DOI: 10.1007/s10103-008-0634-3

11. Dias FJ, Issa JPM, Coutinho-Netto J, Fazan VPS, Sousa LG, Iyomasa MM, et al. Morphometric and high resolution scanning electron microscopy analysis 
of low-level laser therapy and latex protein (hevea brasiliensis) administration following a crush injury of the sciatic nerve in rats. J Neurol Sci; 2015.349(12):129-37. DOI: 10.1016/j.jns.2014.12.043

12. Huisstede BM, Hoogvliet P, Franke TP, Randsdorp MS, Koes BW. Carpal tunnel syndrome: effectiveness of physical therapy and electrophysical modalities. an updated systematic review of randomized controlled trials. Arch Phys Med Rehabil; 2018.99(8):16231634.e23. DOI: 10.1016/j.apmr.2017.08.482

13. Chen YJ, Wang YH, Wang CZ, Ho ML, Kuo PL, Huang MH, et al. Effect of low level laser therapy on chronic compression of the dorsal root ganglion. PLoS One; 2014.9(3):e89894. DOI: 10.1371/journal.pone.0089894

14. Barez MM, Tajziehchi M, Heidari MH, Bushehri A, Moayer F, Mansouri N, et al. Stimulation effect of low level laser therapy on sciatic nerve regeneration in rat. J Lasers Med Sci; 2017.8(Suppl 1):S32-7. DOI: 10.15171/jlms.2017.s7

15. Oliveira Jr HF de, Teixeira ÁH. Mobilização do sistema nervoso: avaliação e tratamento /Mobilization nervous system: assessment and treatment. Fisioter em Mov; 2007.20(3):41-53. Available from: https://periodicos.pucpr.br/index.php/fisio/article/view /18911/18289

16. Castilho J, Ferreira LAB, Pereira WM, Neto HP, Morelli JG da S, Brandalize D, et al. Analysis of electromyographic activity in spastic biceps brachii muscle following neural mobilization. J Bodyw Mov Ther; 2012.16(3):364-8. DOI: 10.1016/j.jbmt.2011.12.003

17. Beneciuk JM, Bishop MD, George SZ. Effects of upper extremity neural mobilization on thermal pain sensitivity: a sham-controlled study in asymptomatic participants. J Orthop Sport Phys Ther; 2009.39(6):428-38. DOI: 10.2519/jospt.2009.2954

18. Véras LST, Vale RG de S, Mello DB de, Castro JAF de, Lima V, Trott A, et al. Electromyography function, disability degree, and pain in leprosy patients undergoing neural mobilization treatment. Rev Soc Bras Med Trop; 2012.45(1):83-8. DOI: http://dx.doi.org/10.1590/S0037-86822012000100016

19. Bennett GJ, Xie YK. A peripheral mononeuropathy in rat that produces disorders of pain sensation like those seen in man. Pain; 1988.33(1):87-107. PubMed: https://www.ncbi.nlm.nih.gov/pubmed/2837713

20. Karvat J, Antunes JS, Bernardino GR, Kakihata CMM, Bertolini GRF. Effect of low-level laser and neural mobilization on nociceptive threshold in experimental sciatica. Rev Dor. 2014;15(3):207-10. DOI: $10.5935 / 1806-0013.20140045$

21. Geuna S, Tos P, Guglielmone R, Battiston B, Giacobini-robecchi MG. Methodological issues in size estimation of myelinated nerve fibers in peripheral nerves. Anat Embryol; 2001.204(1):1-10. PubMed: https://www.ncbi.nlm.nih.gov/pubmed/11506429

22. Sousa FF de A, Ribeiro TL, Fazan VPS, Barbieri CH. Lack of effectiveness of laser therapy applied to the nerve course and the correspondent medullary roots. Acta Ortop Bras; 2013.21(2):92-7. DOI:
10.1590/S1413-78522013000200005

23. Alcântara CC, Gigo-benato D, Salvini TF, Oliveira ALR, Anders JJ, Russo TL. Effect of low-level laser therapy (1llt) on acute neural recovery and inflammation-related gene expression after crush injury in rat sciatic nerve. Lasers Surg Med; 2013.45(4):246-52. DOI: 10.1002/lsm.22129

24. Endo C, Barbieri CH, Mazzer N, Fasan VS. LowPower laser therapy accelerates peripheral nerves' regeneration. Acta Ortop Bras; 2008.16(5):305-10. DOI: $10.1590 / \mathrm{S} 1413-78522008000500011$

25. Martins DF, Mazzardo-martins L, Gadotti VM, Nascimento FP, Lima DAN, Speckhann B, et al. Ankle joint mobilization reduces axonotmesis-induced neuropathic pain and glial activation in the spinal cord and enhances nerve regeneration in rats. Pain; 2011.152(11):2653-61.

DOI: 10.1016/j.pain.2011.08.014

26. Marcioli MAR, Coradini JG, Kunz RI, Ribeiro LDFC, Brancalhão RMC, Bertolini GRF. Nociceptive and histomorphometric evaluation of neural mobilization in experimental injury of the median nerve. ScientificWorldJournal; $2013 . \quad$ DOI: $10.1155 / 2013 / 476890$

27. De-la-Llave-Rincon AI, Ortega-Santiago R, AmbiteQuesada S, Gil-Crujera A, Puentedura EJ, Valenza $\mathrm{MC}$, et al. Response of pain intensity to soft tissue mobilization and neurodynamic technique: a series of 18 patients with chronic carpal tunnel syndrome. J Manip Physiol Ther; 2012;35(6):420-7. DOI: 10.1016/j.jmpt.2012.06.002

28. Oskay D, Meriç A, Kirdi N, Firat T, Ayhan Ç, Leblebicioglu G. Neurodynamic mobilization in the conservative treatment of cubital tunnel syndrome: long-term follow-up of 7 cases. J Manip Physiol Ther; 2010.33(3):156-63. DOI: 10.1016/j.jmpt.2009.12.001

29. Nagrale AV, Patil SP, Gandhi RA, Learman K. Effect of slump stretching versus lumbar mobilization with exercise in subjects with non-radicular low back pain: a randomized clinical trial. J Man Manip Ther; 2012.20(1):35-42.

10.1179/2042618611Y.0000000015

30. Ellis RF, Hing WA. Neural mobilization: a systematic review of randomized controlled trials with an analysis of therapeutic efficacy. J Man Manip Ther; 2008.16(1):8-22. PubMed: https://www.ncbi.nlm.nih.gov/pubmed/19119380

31. Bertolini GRF, Artifon EL, Silva TS da, Cunha DM, Vigo PR. Low-Level laser therapy, at $830 \mathrm{~nm}$, for pain reduction in experimental model of rats with sciatica. Arq Neuropsiquiatr; 2011.69(2-B):356-9. DOI: 10.1590/S0004-282X2011000300017

32. Bertolini GRF, Silva TS, Trindade DL, Carvalho AR. Neural mobilization and static stretching in an experimental sciatica model - an experimental study. Rev Bras Fisioter; 2009.13(6):2-7. DOI: 10.1590/S1413-35552009005000062

33. Ellis A, Bennett DLH. Neuroinflammation and the generation of neuropathic pain. $\mathrm{Br} \mathrm{J}$ Anaesth; 2013.111(1):26-37. DOI: 10.1093/bja/aet128 